\title{
Reflexões sobre o indivíduo desejante e o sofrimento no trabalho: 0 assédio moral, a violência simbólica e o movimento homossexual
}

\author{
Reflections on the desiring individual and suffering at work: workplace bullying, symbolic \\ violence, and the homosexual movement
}

\author{
Alexandre de Pádua Carrieri ${ }^{1}$ \\ Ana Rosa Camillo Aguiar² \\ Ana Paula Rodrigues Diniz ${ }^{3}$
}

\begin{abstract}
Resumo
Este artigo apresenta uma reflexão teórica sobre assédio moral. Mais especificamente, trata-se de uma análise acerca da violência simbólica sofrida pelo trabalhador homossexual, buscando delimitar o contexto social e de produção de subjetividade no qual ocorre tal violência. Os homossexuais, assim como diversas outras minorias sociais, têm sido alvo de violência simbólica nas organizações laborais brasileiras. Este artigo tem sua origem em um projeto de pesquisa acerca de assédio moral sobre trabalhadores masculinos homossexuais em algumas das principais capitais do Brasil e representa uma reflexão final acerca da possibilidade de ir além do conceito de assédio moral, aprofundando o conceito de violência simbólica e introduzindo a violência no espaço social e de produção de subjetividade contemporâneos.
\end{abstract}

Palavras-chave: Violência. Sofrimento no trabalho. Assédio.

\begin{abstract}
This paper presents a theoretical reflection on workplace bullying. More specifically, this is an analysis on the symbolic violence underwent by the homosexual worker, seeking to delimit the social and the subjectivity production context within which such violence occurs. Homosexuals, like many other social minorities, have been the target of symbolic violence in Brazilian labor organizations. This paper has as its origin a research project on workplace bullying towards homosexual male workers in some major cities in Brazil and it represents an ultimate reflection on the possibility of going beyond the concept of workplace bullying, deepening the concept of symbolic violence and introducing violence into the social and the contemporary subjectivity production space.
\end{abstract}

Keywords: Violence. Suffering at work. Harassment.

Artigo submetido em 27 de junho de 2012 e aceito para publicação em 27 de janeiro de 2013.

1 Professor titular da FACE/UFMG; Coordenador do NEOS - Faculdade de Ciências Econômicas. Endereço: Rua Newton, 275, CEP 30360-200, Belo Horizonte - MG, Brasil. E-mail: alexandre@face.ufmg.br

2 Mestre em Administração pela Universidade Federal de Lavras/ UFLA; Pesquisadora do NEOS. Endereço: Rua Newton, 275, CEP 30360-200, Belo Horizonte - MG, Brasil. E-mail: rosacamillo@gmail.com

${ }^{3}$ Mestre em Administração pelo Cepead/ UFMG; Pesquisadora do NEOS - Faculdade de Ciências Econômicas -UFMG. Endereço: Av. Antônio Carlos, 6627, Pampulha, CEP 31270-654, Belo Horizonte - MG, Brasil. E-mail: anaprdiniz@hotmail.com 


\section{Introdução}

Este artigo apresenta uma reflexão teórica sobre o assédio moral como violência simbólica, sob a forma de conflito que se estabelece entre o sujeito desejante, que acredita ser possível expressar sua singularidade, mas que se depara com as exigências modernas do capital em relação ao trabalho individualizado, do cada um por si, da exigência de desempenho, da alta empregabilidade, da empresabilidade e outros aforismos criados pela gestão das organizações. O resultado de tal conflito assume formas de sofrimento no trabalho, assunto importante e, até certo ponto, esquecido pela sociedade.

Sob a perspectiva de Dejours (1992), o sofrimento no trabalho surge como um conflito entre a história do indivíduo desejante e a gestão da organização, que ignora as particularidades subjetivas. O assédio moral como violência simbólica apareceria no contexto no qual o sujeito desejante (que, pelo menos, acredita-se desejante) depara-se com os empecilhos do mundo do trabalho.

Mais especificamente, neste artigo é apresentada uma reflexão acerca da violência simbólica exercida sobre o trabalhador homossexual. Entende-se, aqui, que o homossexual, assim como a mulher, o negro e qualquer outra minoria social, tem sido alvo de violência simbólica nas organizações brasileiras. As políticas de diversidade dentro das organizações, que visam a integrar esses grupos, são um reflexo e resultado do malestar causado pelas expressões de violência. Analisa-se o trabalhador homossexual dentro da sociedade do espetáculo, marcada pela cultura do narcisismo (BIRMAN, 2007). Assim, entende-se que o sujeito desejante e sua subjetividade estão inseridos em uma sociedade que valoriza o consumo, o individualismo e a dominação masculina heterossexual. A gestão das organizações, além disso, fomenta a competição, as competências, o desenvolvimento de talentos, a liderança etc. Esse sujeito inserido nesse espaço organizacional - pode ser vítima de assédio moral, entendido como violência simbólica. Aqui, busca-se ultrapassar a noção de assédio, predominante nos estudos organizacionais e nas análises do campo do direito, como conduta abusiva, traduzida pela linguagem e pelos atos que incidem sobre os sujeitos, sua personalidade, sua dignidade e sua integridade física ou psíquica (HIRIGOYEN, 2005). Atos e/ou palavras que se repetem no tempo e levam a quadros específicos de adoecimento físico e psíquico. Neste artigo, buscamos a transmutação do termo assédio para violência simbólica.

Este artigo advém de projeto de pesquisa acerca de assédio moral sobre trabalhadores masculinos homossexuais em algumas das principais capitais do Brasil. Ao final do projeto, a partir do qual foram produzidos alguns artigos sobre o tema assédio e violência simbólica, sentiu-se a necessidade de revisitar e refletir sobre as análises realizadas, pontuando a possibilidade de ir além do conceito de assédio moral, aprofundando o conceito de violência simbólica e inscrevendo a violência no espaço social e de produção de subjetividade contemporâneos; espaço percebido como marcado pelo individualismo e pela cultura do narcisismo. Além disso, revimos a necessidade de situar o sujeito/trabalhador homossexual diante do discurso do movimento gay, produtor de novas subjetividades.

O texto está dividido em cinco partes. Após esta introdução, na segunda parte, contextualiza-se o sujeito desejante na sociedade individualista; na terceira parte, faz-se uma reflexão sobre o assédio moral e a violência simbólica, percebendo-os como desencadeadores de sofrimento no trabalho; a quarta parte aborda o trabalhador homossexual inserido na discursividade do movimento gay; e, por fim, na quinta parte são tecidas as considerações finais.

\section{Contexto Atual: O Sujeito Desejante na Sociedade Individualista}

A cultura moderna valoriza e fomenta o indivíduo livre, que busca a satisfação do seu desejo, o sujeito narcísico e hedonista. Para Lipovetsky (1983), os discursos que fundam a ação humana baseada no consumo favoreceram o desenvolvimento dos desejos e, também, dos direitos do indivíduo. Estaríamos na era do 
querer, da autossatisfação exacerbada, um querer contínuo e uma satisfação fugaz, ou melhor, uma insatisfação constante.

Na concepção de Débord (1997), o homem vive na sociedade do espetáculo, na qual se acredita ser livre e poder escolher como viver. Contudo, ele é um consumidor de ilusões, as quais escolhe, pois o desejo humano é construído e o homem acaba assujeitado por esse desejo. Nessa ilusão, busca a satisfação irrestrita, o gozo intermitente. Nessa perspectiva, o individualismo é incentivado e posto socialmente como algo positivo (JARDIM, 2004).

Ainda de acordo com esse autor, o homem é livre e desejante no limite dos moldes culturais do sistema socioeconômico no qual se insere. Assim, quando um indivíduo se mostra singular, distinto do sistema e dos outros indivíduos, ele sofre com os preconceitos de uma sociedade que aparenta zelar pela liberdade e pela singularidade. Essa afirmação, no tocante à manifestação do desejo no mundo do trabalho, parece ter maior assertividade. Como sujeito de consumo, o desejo no mundo social seria tido como livre, ao passo que, como trabalhador, o indivíduo se depara com os ditames do mundo do trabalho, no qual a diversidade parece tomar formas de simples retórica. Se, por um lado, a sociedade espetacular lhe sugere a liberdade, sugere a ele a fetichização de si mesmo como sujeito livre, por outro, as organizações do trabalho, também operam com a imagem, com o parecer ser. Assim, a imagem sobrepõe-se à realidade e mascaram-se os conflitos e as dificuldades do simbólico arraigado no cotidiano. O sofrimento no trabalho surge nesse conflito entre ser livre e consumir o que se deseja e ser um trabalhador explorado, com recursos finitos, assujeitado pelo desejo infinito (DEJOURS, 1999; MERLO, 2000).

Jota (2007), estudando a sexualidade feminina, reporta-se a esse sujeito inserido na sociedade contemporânea. Para o autor, a transformação dos estilos de vida e a valorização do consumo geraram uma cultura do individualismo, da expressão do desejo. Para Birman (2007, p. 24), "os destinos do desejo assumem, pois, uma direção marcadamente exibicionista e autocentrada, na qual o horizonte intersubjetivo se encontra esvaziado e desinvestido de trocas inter humanas".

$\mathrm{Na}$ atualidade, observa-se que os sujeitos homossexuais têm buscado uma nova relação com a sociedade, tentando construir um novo espaço social, recusando a marginalização e a exclusão. A construção e a reivindicação de aceitação e de integração sociocultural tornaram possíveis o contexto de destaque ao indivíduo e a sua subjetividade na contemporaneidade.

O discurso do movimento homossexual, da busca de direitos dos sujeitos homossexuais, surge nesse contexto como uma possibilidade da cultura dos tempos modernos, a possibilidade da liberdade de expressão do desejo. O movimento político social da "causa gay" encontra ressonância na sociedade que valoriza o indivíduo. O desejo individual coaduna-se com o coletivo, com o desejo de reconhecimento público, com as ideias de uma sociedade que abriga a diversidade e na qual é possível a constituição de novas identidades sociais e individuais.

Contudo, o sofrimento no trabalho surge como um conflito entre a história do indivíduo desejante e a gestão da organização, que, quando não a ignora, mascara-a, por não conseguir romper com os ditames da constituição simbólica da heteronormatividade e reconhecer a diferença como parte das relações sociais. Em uma sociedade do espetáculo, da aparência, os sujeitos narcísicos, individualistas, não se percebem como parte do laço social e como envolvidos por ele, limitando-se simbolicamente às possibilidades de ressignificar seus desejos e lugares sociais.

\section{Do Assédio à Violência Simbólica: De Qualquer Modo, Sofrimento no Trabalho}

As humilhações no trabalho são tão antigas quanto a própria divisão do trabalho. Elas se tornaram as bases da intensificação da produtividade dos trabalhadores desde a Antiguidade, passando pela Escravidão até a 
Contemporaneidade, que é marcada pelas práticas neoliberais de mercado. Nas últimas décadas do século XX, o mundo do trabalho foi palco de grandes mudanças no cenário de organização e das relações de trabalho, as quais influenciaram de forma decisiva a relação entre trabalhadores (DEJOURS, 1999).

\section{Sofrimento no trabalho}

O tema sofrimento no trabalho tem como referência teórica inicial os estudos de Dejours (1992), que, nesse mesmo ano, teve seu primeiro texto publicado no Brasil, enfocando a loucura do trabalho, um estudo de psicopatologia do trabalho no qual denunciava o sintoma da sociedade contemporânea (o sofrimento no trabalho) como um conflito entre a história individual "portadora de projetos de esperanças, de desejos e uma organização do trabalho que os ignora". O sofrimento decorreria desse conflito, à medida que o sujeito não consegue alterar o trabalho "tarefa" em conformidade com "suas necessidades fisiológicas e seus desejos psicológicos".

Os estudos de Christophe Dejours são apresentados e revisitados por Lancman e Sznelwar (2008), que ressaltam que os estudos empíricos de Dejours mostravam que, apesar do sofrimento, a maioria dos trabalhadores não adoecia, mas desenvolvia estratégias pra lidar com as situações que poderiam provocar o adoecimento, uma vez que:

[...] A proteção da saúde mental não depende apenas do talento de cada individuo [...], essa proteção passa também pelas estratégias coletivas de defesa, que desempenham um papel relevante nas capacidades de cada um na resistência aos efeitos desestabilizadores do sofrimento (DEJOURS, 2008, p. 19).

Dejours (2008) analisa o mundo do trabalho marcado pela cultura do individualismo, da competição permanente, da banalização de comportamentos desleais, dos despolitizados. Para o autor "o trabalho pode se tornar uma perigosa força de destruição da democracia e de difusão do cinismo e do cada um por si" (DEJOURS, 2008, p. 60). O contexto atual de enfraquecimento das estruturas sindicais e de desarticulação das redes sociais de solidariedade seria responsável pelo enfraquecimento das defesas coletivas diante das estratégias do capital, favorecedoras de situações de sofrimento.

Molinier (1995), Merlo (2000) e Lancman (2008) afirmam que o trabalho tem várias dimensões no mundo social, o ato de trabalhar constitui mais que a simples venda da força de trabalho: existiria a remuneração social pelo trabalho, isto é, o trabalho como fator de integração social. Segundo Lancman (2008, p. 24):

[...] O trabalho tem, ainda, uma função psíquica: é um dos alicerces de constituição do sujeito e de sua rede de significados. Processos como reconhecimento, gratificação, mobilização da inteligência, mais que relacionados à realização do trabalho, estão ligados à constituição da identidade e da subjetividade.

Sob essa perspectiva, o trabalho é tido como edificador de identidades individuais e coletivas, já o trabalhador é visto, pela psicodinâmica do trabalho (MOLINIER, 1995; DEJOURS, 2008), como atuante diante da realidade do trabalho que busca subjugá-lo; por isso, procura criar estratégias defensivas diante de situações que o oprimem e que não correspondem aos seus desejos de expressão no mundo do trabalho. Sob essa ótica, o trabalhador é visto como ser capaz de reapropriar, de transformar, de reconstruir a realidade.

Dejours (2008) altera seu objeto de estudos anterior, o qual era a análise do sofrimento psíquico resultante do conflito entre o desejo do sujeito e a organização do trabalho, passando a ser os processos intersubjetivos das diversas situações de trabalho. Para o autor, portanto, o foco passa a ser as situações vividas no trabalho no qual os sujeitos se apresentam psiquicamente instáveis, buscando o reconhecimento de seu trabalho e utilizando-se de mecanismos de defesa contra situações que podem gerar sofrimento. 
Nos seus estudos, Dejours (1999) mostra que a virilidade, como manifestação de poder sobre o outro, surge como defesa diante de situações de insegurança, medo no trabalho; sendo compartilhada pelos membros de um coletivo de trabalho.

Já para Molinier (2004, p. 23):

As duplas virilidade-masculinidade, mulheridade-feminilidade não são, então, simétricas e não reenviam a uma tipologia das identidades sexuadas, mas formam uma rede conceitual topológica para pensar a complexidade dos destinos de identidades, entre sexualidade e trabalho, sem fixar ou definir a essência dos conteúdos da masculinidade ou da feminilidade.

Em sua pesquisa, esse autor aponta as dificuldades subjetivas das mulheres no trabalho, no lidar com posições estereotipadas socialmente do lugar sexual de cada sujeito. Assim, a psicodinâmica do trabalho concebe o lugar sexual como central no entendimento do sofrimento do trabalho.

Dentre as formas que levam ao sofrimento no trabalho, Dejours (2008) comenta que as práticas de assédio moral têm sido bastante recorrentes, sendo que o assédio moral não é um tema novo; para o autor, os chefes, aqueles em posição hierárquica superior, sempre perseguiram os trabalhadores, notadamente aqueles em posições hierárquicas inferiores. Contudo, atualmente é preocupante o crescimento desmesurado das patologias causadas pelas perseguições. Assim como ocorreu uma generalização, nas organizações, dessas práticas de perseguição, agora elas também ocorrem entre trabalhadores do mesmo nível hierárquico. Dejours (2008) ressalta como causas desse estado de coisas o exacerbado individualismo e a falta de solidariedade entre os trabalhadores.

\section{Assédio moral}

Nas últimas décadas do século XX, o mundo do trabalho foi palco de grandes mudanças nas relações de trabalho e nos cenários da gestão organizacional, as quais influenciaram de forma decisiva a relação entre trabalhadores. Sato (2002) discute tal tema na psicologia social e descreve o mundo do trabalho no Brasil como diverso, no qual novas e velhas formas materiais e simbólicas de controle do trabalho convivem lado a lado no mesmo chão de fábrica, existindo processos de trabalho nos quais sujeitos são colocados como incapazes, apáticos e ociosos ao lado de processos de trabalho nos quais o controle é subjetivo, simbólico. O trabalhador é colocado como responsável e "gestor" do seu trabalho, embora ele prescinda de controles externos, pois o controle simbólico, panopticamente desenvolvido pelos novos processos de gestão, parece ser muito eficaz.

Para Lima (1998), a redução de postos de trabalho, com o subsequente aumento do risco de desemprego, a precarização das condições de trabalho e a ênfase na produtividade e na competitividade tornaram ainda mais fragilizadas e estressantes as relações de trabalho no Brasil, o que acabou por propiciar maior visibilidade aos conflitos internos ocorridos nos ambientes organizacionais antes não aflorados ou pouco expostos. Esses conflitos evidenciam uma crescente violência no espaço do trabalho, que passou a ser percebida como desencadeadora de sofrimento e de adoecimento psíquico.

$\mathrm{Na}$ administração, no tocante aos estudos organizacionais, o adoecimento no trabalho é enfocado sob como as formas de gestão contemporânea têm impactado o trabalhador no seu bem-estar. A discussão acerca da temática assédio moral tomou uma dimensão considerável a partir de 1990, no contexto das atuais demandas organizacionais que transformam o ambiente de trabalho, exigindo do trabalhador maior produtividade e adequação às normas vigentes, o que propicia que as relações humanas tornem-se mais fragilizadas e marcadas pela violência. 
O assédio moral surge no âmbito dos estudos organizacionais como caracterizado pelas formas de violência que destroem as relações de trabalho, adoecendo indivíduos, causando danos à sua saúde física e/ou psíquica, além de reduzir sua produtividade, favorecendo o absenteísmo, a rotatividade e a demissão de funcionários por desgaste psicológico e debilidade física. Em relação a esses temas, destacam-se os estudos de Barreto (2003; 2005), Freitas (2001) e Freitas, Heloani e Barreto (2008), que vêm, ao longo da última década, mostrando as expressões do assédio moral nas organizações contemporâneas como reflexo do mal-estar nas relações de trabalho.

Esses vários estudos têm como base conceitual a obra de Hirigoyen (2005), autora que se debruçou sobre o tema desde 1998. Nessa publicação, a autora discorre sobre uma violência que se dirige agressivamente contra a identidade do outro, constituindo-se em um processo de destruição moral, abusivo. A pesquisadora reporta que se inicia de forma sutil e que, por sua constância, repetição, acua a vítima em uma posição de violentada.

O conceito de assédio moral em Hirigoyen (2005, p. 65) refere-se a "toda e qualquer conduta abusiva manifestando-se, sobretudo, por comportamentos, palavras, atos, gestos, escritos que possam trazer dano à personalidade, à dignidade ou à integridade física ou psíquica". A autora mostra o assédio moral como destruidor do ambiente de trabalho, diminuindo a produtividade dos profissionais, favorecendo o absenteísmo, podendo trazer danos psíquicos ao assediado.

No Brasil, mais descritiva e abrangentemente, Barreto (2005, p. 49-50) definiu o assédio como:

[...] Uma forma sutil de violência que envolve e abrange múltiplos danos, tanto de bens materiais como morais, no âmbito das relações laborais. O que se verifica no assédio é a repetição do ato que viola intencionalmente os direitos do outro, atingindo sua integridade biológica e causando transtornos à saúde psíquica e física. Compreende um conjunto de sinais em que se estabelece um cerco ao outro sem lhe dar tréguas. Sua intencionalidade é exercer o domínio, quebrar a vontade do outro, impondo término ao conflito quer pela via da demissão ou sujeição. É um processo, mediado por palavras, símbolos e sinais, que, estabelecidos, impõem ao outro a obediência cega sem questionamentos ou explicações. Deve "aceitar" provocações, gozações, desqualificações e ridicularizações de formas constantes e repetitivas sem reclamar ou questionar.

Hirigoyen (2002) redefine o assédio moral, equivalendo-o a uma "guerra psicológica", que envolveria abuso de poder e manipulação perversa, fatores responsáveis por prejuízos à saúde mental e física das pessoas, identificando dois fatores que compõem o assédio moral nas organizações. O primeiro seria a manipulação perversa, na qual o assediador sente satisfação em manipular o outro, colocando-o em uma situação de impossibilidade de ação, para, depois, aniquilá-lo, sem que o perverso sofra nenhuma penalidade por isso por parte da organização ou sem que sinta culpa. O segundo seria o abuso de poder, que surge como o efeito da imposição da vontade de um sobre o outro. $\mathrm{O}$ abuso se caracterizaria pelo uso ilegal ou coercivo de tal poder para atingir determinado fim. O expoente máximo do abuso do poder é a submissão do indivíduo a diversas formas de servidão.

Um tema importante, mas ainda pouco explorado nos estudos organizacionais, é a perversão. Para Hirigoyen (2002) o agressor é designado como indivíduo perverso, isto é, constitui-se como um sujeito capaz de praticar atitudes perversas. Perversão significa voltar-se para outro lado, retornar, reverter; indica o que está às avessas, o que está fora de ordem, desregrado, contrário ao que se deve ser, defeituoso, vicioso (LANTÉRI-LAURA, 1994). O ato perverso pode ser visto como um ato amoral, de subjugação do outro, no qual alguém busca insidiosamente colocar o outro como objeto passivo de sua ação agressiva. Hirigoyen (2005, p. 13) não define perversão, mas aponta que há uma intenção consciente no assédio moral, na qual "a perversidade não provém de um problema psiquiátrico, mas de uma racionalidade fria combinada a uma incapacidade de considerar os outros como seres humanos". 
A intensificação, a gravidade e a amplitude do assédio moral em organizações brasileiras têm reflexos no campo do direito trabalhista. Garbin (2009), estudando o assédio na mídia impressa, discorre que a natureza jurídica do assédio pode levar à classificação como dano moral ou discriminação. Caso o assédio seja classificado como discriminação, trabalha-se na esfera dos direitos do trabalhador; se for classificado como dano moral, opera-se com a violação dos direitos da personalidade do indivíduo. No caso particular de dano moral, são atingidos os direitos personalíssimos do indivíduo, caracterizados como aqueles do foro íntimo da pessoa, tais como honra, liberdade, intimidade e imagem.

Sob o aspecto jurídico há a necessidade de demonstrar uma relação de causalidade entre os transtornos mentais decorrentes de situações de assédio moral e aspectos organizacionais de trabalho. Garbin (2009) afirma, ainda, a necessidade jurídica de caracterizar o assédio moral como acidente de trabalho, dado que tem origem no trabalho e nele se desenvolve, levando a problemas orgânicos e psíquicos. Sob essa perspectiva, o assédio é visto como desencadeador de doença no trabalho; e o reconhecimento do adoecimento no trabalho passa pelo estabelecimento de nexos causais entre transtornos mentais e aspectos organizacionais do trabalho.

Nascimento (2004) também discute o assédio no campo do direito, mostrando que ele pode se inserir no âmbito do dano moral como no âmbito da discriminação. Para a autora:

[A] jurisprudência já se manifestou no sentido de que o assédio moral é uma espécie do gênero dano moral e que se caracteriza com o resultado de uma conduta que viola os direitos da personalidade do indivíduo. A moral, portanto, é um atributo da personalidade. O dano moral, em consequência, é aquele que afeta a própria personalidade humana. [...] como se vê, o dano moral decorre da ofensa ao direito personalíssimo da vítima. (TST, $18^{\mathrm{a}}$ R., $1^{\text {a }}$ T., RR 577.297, rel. Juiz Convocado Aloysio Corrêa da Veiga, j. 05/11/2003) (NASCIMENTO, 2004, p. 4-5).

Nessa direção, jurídica, o assédio gera a obrigação de se reparar o dano moral causado por discriminação, o qual viola o direito personalíssimo do sujeito.

Ainda segundo essa autora, o ato de assédio moral no direito trabalhista pode ser observado quando a conduta do agressor é vexatória, gerando a marginalização do sujeito mediante o isolamento social, a difamação, a atribuição de tarefas consideradas humilhantes. Como consequência, surgem as enfermidades ligadas à saúde mental e física da vitima. A autora deixa clara a necessidade jurídica de demonstração do ato de assédio como ato repetitivo (não esporádico), porque, de acordo com o Acórdão n. 9.029/2002 do TRT da $17^{a}$ Região, 1142.2001.006.17.00.9, publicado em 15/10/2002, podemos constatar que:

A humilhação repetitiva e de longa duração interfere na vida do assediado de modo direto, comprometendo sua identidade, dignidade e relações afetivas e sociais, ocasionando graves danos à saúde física e mental, que podem evoluir para a incapacidade laborativa, desemprego ou mesmo a morte, constituindo um risco invisível, porém, concreto, nas relações e condições de trabalho (NASCIMENTO, 2004, p. 9).

Juridicamente, Nascimento (2004) considera que, para que o assédio moral se configure como tal, é necessária a existência do dano psíquico-emocional, exigindo perícia por psiquiatra e outros especialistas.

Outro autor que discute o assédio moral no direito é Armada (2006). Para este, o tema do assédio moral no direito trabalhista é tratado como dano moral, sendo que, com a Constituição Federal de 1988, pelo destaque à honra e à dignidade da pessoa humana, esse tema obteve maior expressão jurídica. $\mathrm{O}$ autor mostra que, no Código Civil, as ações praticadas pelo assediador configuram abuso de direito, ato ilícito, uma vez que, segundo o art. 187 desse nosso código, "comete ato ilícito o titular de um direito que, ao exercê-lo, excede manifestamente os limites impostos pelo seu fim econômico e social e pela boa-fé". Assim: 
[...] É passível de indenização pecuniária o ato cometido pelo empregador que, contrariando os princípios de respeito mútuo norteadores do contrato de trabalho, atinge os bens subjetivos inerentes à pessoa humana, tais quais a reputação, a honra, a liberdade, o decoro, a imagem e a dignidade, acarretando evidente prejuízo ao empregado no âmbito das relações sociais (ARMADA, 2006, p. 8).

O olhar do campo do direito coaduna-se com as análises organizacionais quanto aos preceitos de necessidade de repetição no tempo. Para Freitas (2001), é importante distinguir o assédio de outros conflitos comuns no espaço do trabalho já que "é a repetição das situações que vexam o outro e das humilhações sem nenhuma nuance que constitui o fenômeno destruidor" (FREITAS, 2001, p. 10). Hirigoyen (2002, p. 30) também aponta a repetição como uma característica de assédio: "o assédio moral caracteriza-se antes de tudo pela repetição".

Observa-se que as discussões sobre assédio, que apontam a necessidade de recursividade, têm suas relações diretas com presunções do direito trabalhista. As preocupações em estabelecer nexos causais entre o assédio no trabalho e quadros nosológicos específicos do adoecimento do trabalhador também se inscrevem dentro dessa preocupação. Apesar de reducionistas, são necessárias dentro de tal espectro. Segundo Hirigoyen (2002), o que é novo em relação ao assédio moral reside na intensificação, na gravidade, na amplitude, na banalização do fenômeno e na abordagem que tenta estabelecer o nexo causal com a organização do trabalho e tratá-lo como não inerente ao trabalho, mas relativo às condições em que este é realizado.

Em direção distinta, pode-se questionar a ideia de haver necessidade de recursividade para se caracterizar o assédio moral. O foco pode recair sobre o sujeito e a sua vivência de ser assediado. A necessidade de recursividade limita as possibilidades de entendimento do vivido, pois restringe as percepções do sujeito àquilo que o pesquisador entende como assédio, negando as vivências e análises que não se adequem ao conceito estipulado.

Deve-se destacar que há a necessidade de analisar a violência sofrida pelo trabalhador para além do assédio. Freitas, Heloani e Barreto (2008, p. XVI) comentam que:

[...] Violência expressa no ambiente de trabalho contemporâneo pode ser uma manifestação de uma violência maior que encontra seus fundamentos [...] em uma organização do trabalho cada vez mais sem compromisso com o ser humano [...] trata-se, portanto, de uma violência assumida como um efeito colateral simplesmente, ou seja, uma violência que se quer naturalizada.

A violência, ao ser colocada como não decorrente da organização do trabalho, mas de aspectos deturpados de sua execução, opera destituindo o trabalho de seu papel na edificação de identidade do sujeito.

\section{Violência simbólica}

Zaluar e Leal (2001) analisam que grande parte dos estudos brasileiros sobre violência tem como referência Arendt, ao caracterizar a violência como um instrumento e não um fim, sendo que, se esses instrumentos seriam mudos, abdicariam do uso da linguagem que caracteriza as relações de poder, baseadas na persuasão, influência ou legitimidade. As autoras analisam que, dentre os diversos estudos sobre violência, há pouco espaço para o aparecimento do sujeito da argumentação, da negociação, pois esse sujeito estaria submisso/passivo diante da força física do agressor e/ou achatado pelo despótico poder da negação do diálogo. 
Zaluar e Leal (2001) evidenciam que a violência pode ser estudada com base nos trabalhos de Foucault e de Bourdieu. A violência pode ser apreendida como uma forma de sociabilidade, que validaria normas sociais e como um dispositivo de poder e de controle. Para as autoras, a violência impediria o reconhecimento do outro, seja esse outro uma pessoa, um homem ou mulher, preto ou branco, pobre ou rico, isso é, a violência, pelo uso da força física ou simbólica, causaria o impedimento do reconhecimento do outro em seus atributos de identidade pessoal.

Tal olhar sobre a violência é baseada na concepção de Bourdieu (2007, p. 14-15) de poder simbólico como:

[...] poder de construir o dado pela enunciação, de fazer ver e fazer crer, de confirmar ou de transformar a visão do mundo e, desse modo, a ação sobre o mundo, portanto, o mundo, poder quase mágico que permite obter o equivalente daquilo que é obtido pela força (física ou econômica) graças ao efeito específico de mobilização, só se exerce se for reconhecido, quer dizer, ignorado como arbitrário.

Bourdieu (1983) propõe a categoria de violência simbólica, dentro de um olhar sobre as relações de força e poder que se instituem a dinâmica social. Para o autor, as relações sociais se dão em campos, formados por estruturas objetivas e subjetivas, nos quais os agentes buscam adquirir capitais simbólicos (capital econômico, cultural e social). O campo ou espaço social opera com valores e regras próprias; agregando indivíduos e grupos que possuem o mesmo habitus.

Para Bordieu (1983, p. 33), o habitus é:

[...] Um sistema de disposições duráveis e transponíveis que, integrando todas as experiências passadas, funciona a cada momento como uma matriz de percepções, de apreciações e de ações - e torna possível a realização de tarefas infinitamente diferenciadas, graças às transferências analógicas de esquemas.

Esse conceito de habitus proposto por Bordieu refere-se a esquemas, formatações da subjetividade individual produzidas socialmente, que orientam o agir humano. Nessa perspectiva, há uma relação de mão dupla, de inter-relação entre a subjetividade e a estrutura de um campo, construídos socialmente. Thiry-Cherques (2006, p. 35) afirma que "o habitus é a internalização ou incorporação da estrutura social, enquanto o campo é a exteriorização ou objetivação do habitus". Existem propriedades que são comuns a todos os campos. Além de seu habitus específico e estrutura, o campo é dotado de doxa ou opinião consensual; de nomos, leis, formais ou não, que normatizam a disputa pela dominação, e dos capitais caracterizados pelos interesses em determinado campo.

Para compreensão de como se processa a apreensão do mundo pela subjetividade humana, Bordieu (1983) caracteriza o habitus como constituído de três dimensões: o hexis, o eidos e o éthos. O hexis faz referência aos princípios interiorizados pelo corpo, as posturas, as condutas e as expressões corporais. O eidos se refere a uma dimensão dos esquemas de classificação/ordenação das coisas no mundo; princípio de uma construção imaginária do real; que se configura nos julgamentos morais e estéticos, expressos na conduta dos agentes. Por fim, o éthos é a dimensão ética que orienta a prática cotidiana.

Assim, o sujeito possui uma relação com os outros de partilha de esquemas de apreciação e percepção, dentro de um espaço social, um campo. Contudo, há conflito, na busca pela detenção de capital. Há a dominação e a violência simbólica, violência silenciosa na qual as coisas as percepções são naturalizadas. O senso comum que se configura no habitus dos sujeitos e grupos, reforçando posições e interesses de agentes que detêm o poder social. A violência (simbólica) se dá pela imposição de modos de perceber a realidade, definidos pelos interesses de determinados grupos sociais. É uma violência institucionalizada, que se reproduz na diferenciação e na exclusão de ideias, modos de ver e agir de uns em detrimento da valorização, da legitimação de outros. 
A ideia do que é "natural" entre os grupos sociais é uma das principais categorias legitimadoras de modos dominantes de existir e perceber a realidade (BOURDIEU, 1996). Tal distinção do que é "natural" e " normal" na sociedade exclui todas as demais possibilidades, tornando-as não possíveis.

A violência (simbólica) difunde os interesses das classes hegemônicas. Ela se institucionaliza e se reproduz graças à construção sócio-histórica da desigualdade e da exclusão dos dominados, por meio do trabalho de agentes e instituições específicos, tais como a família, a Igreja, a escola e o Estado. A sociedade, como espaço social, é uma estrutura de diferença que foi fundamentada na objetividade, por interesses de classe, através da valorização e da legitimação de certas formas de poder ou tipos de capital, entendidos como eficientes para aquele dado universo social, e, destarte, estabeleceu-se uma "distinção natural" entre os grupos. O processo fundador dessa fantasia, a "distinção natural", assenta-se sobre o poder da classe dominante de deliberar a acepção de excelência, a qual se refere, obviamente, à sua maneira de existir (BOURDIEU, 1996). Tal distinção natural traz o discurso do que é normal na sociedade, criando um padrão do que é ser distinto, do que é validado.

O preconceito que caracteriza a exclusão daqueles que se distanciam do "padrão de normalidade" social caracteriza uma manifestação insidiosa da violência simbólica. Entre as diversas formas de preconceito advindas do mundo social, destacam-se as direcionadas à homossexualidade.

A heteronormatividade expressa a violência simbólica impetrada nas organizações sociais a respeito da homossexualidade. A separação de indivíduos, sua classificação em homossexuais e heterossexuais caracteriza a distinção. Realizada a distinção no mundo social, há que se voltar o olhar sobre como tal distinção opera no espaço das organizações de trabalho. Há, também, a necessidade de se perceber a disputa/luta pela dominação que se opera nesse campo. Sob enfoque de Bordieu, o trabalhador homossexual vive em um campo de conflito, existindo a busca de produção de novas verdades, pelo domínio do simbólico.

\section{O Trabalhador Homossexual e o Movimento Gay como Imperativo-Mestre}

Ao se analisar o assédio moral e a violência simbólica contextualizados nos ambientes organizacionais, há que se levar em conta, além das dimensões de raça e de gênero, da posição na organização, da classe social e da escolaridade, as dimensões de orientação sexual. A sexualidade ainda é pouco discutida no ambiente organizacional, o que é um equívoco, dados seus efeitos potenciais na vida do indivíduo e dos grupos aos quais pertence.

A Conferência Internacional do Trabalho ocorrida em Genebra em 2007 alertou sobre a discriminação baseada na orientação sexual. Constatou-se que as instituições e os mecanismos de direitos humanos de âmbito nacional ou internacional estão em um processo de outorga, dando cada vez mais importância à luta contra a discriminação baseada na orientação sexual. Contudo, alerta-se que, em alguns países, os trabalhadores podem sofrer discriminação nos locais de trabalho se há suspeita de que são lésbicas, gays, bissexuais ou transexuais. As pessoas cuja orientação sexual não se insere nos modelos estabelecidos podem ser objeto de violência verbal, psicológica e física, além de ser alvo de manifestações de ódio. Além disso, a homossexualidade é ilegal em vários países e em muitos é penalizada com castigo corporal ou prisão (OIT, 2007).

Apoiando-se no conceito de dispositivo contido em Foucault, Nardi (2007) afirma que, em nossa sociedade, existem dois dispositivos centrais - o trabalho e a sexualidade - que funcionam como organizadores da vida social e que são criadores de subjetividades. Assim, o autor salienta que, com a biopolítica, somos chamados à responsabilidade e à produção, ou melhor, somos corresponsáveis pela riqueza de uma nação e, por outro lado, temos de reproduzir-nos seguindo um modelo de família heterossexual monogâmica. 
A gestão das organizações tem apostado na construção de novas interações de trabalho caracterizadas pelo reconhecimento e pela valorização da criatividade e da subjetividade. A gestão passou, então, a trabalhar na construção do envolvimento dos trabalhadores através de uma imagem onírica, na qual:

[...] O fetiche da igualdade torna-se o mediador das relações entre os atores, contribuindo para encurtar as distâncias sociais e mascarar os conflitos, negando-os sob a forma de um consenso utópico. Aqui, a cultura da "dádiva" enraíza-se, fazendo de cada trabalhador um "devedor" que percebe e elabora um novo significado para a empresa, composta de uma aura e de um clima especial (PIMENTA e CORREA, 2001, p. 231).

A gestão de pessoas estaria preocupada com a atração e a retenção de "talentos", instituindo e difundindo as políticas de diversidade sexual, sendo que "a área de Recursos Humanos é responsável pelo cumprimento de metas no que diz respeito à contratação de pessoas dos grupos-alvo da política de diversidade e ao gerenciamento da diversidade dentro da empresa" (GALEÃO-SILVA e ALVES, 2002, p. 7). O intuito dessa política é, basicamente, combater o preconceito sexual dentro das organizações, o que não se efetivou em plenitude, uma vez que "o preconceito está arraigado no campo das ideias e manifesta-se mesmo onde se diz combatê-lo" (GALEÃO-SILVA e ALVES, 2002, p. 9), porquanto a discriminação pode ser eliminada somente com a suplantação da ideologia que a fundamenta.

Eccel e Flores-Pereira (2008) garantem que as políticas de diversidade não promovem a igualdade por meio da melhoria das condições de trabalho, bem como não aumentam as oportunidades para os grupos discriminados. Assim, as autoras afirmam que as políticas de diversidade acabam mascarando "as diferenças, pois excluem o seu caráter político, e tomam a diversidade como mais um recurso organizacional a ser administrado em busca de melhores resultados [...]" (ECCEL e FLORES-PEREIRA, 2008, p. 4). Além disso, concluem que as políticas de diversidade voltadas a homossexuais acabam reafirmando e mantendo a hegemonia do que é considerado "normal" (heterossexual) e a desvalorização de tudo que é diferente.

Herek (1991) afirma que a hostilidade para com pessoas homossexuais tem sido denominada de diversas formas: homofobia, heterossexismo, homossexofobia, homossexismo, homonegativismo, antihomossexualismo e anti-homossexualidade. Desses termos, o mais comumente usado na literatura é homofobia.

Autores como Croteau e Hedstrom (1993), Elliot (1993) e Molinier (1995) afirmam haver barreiras encontradas por pessoas de orientação não heterossexual no ambiente de trabalho, como discriminação, homofobia, estereótipos negativos, estigmas sociais e o medo da aids. De forma geral, ainda existem, nas relações de trabalho, trabalhadores homossexuais que deixam de ser contratados, que são despedidos ou que têm sua carreira profissional prejudicada por fatores os quais se prendem claramente à orientação sexual inferida ou assumida. Para os autores, esse preconceito arraigado na mentalidade heterossexista, ou até mesmo homofóbica, de muitos empregadores, não é embasado em qualquer prova ou fundamento que justifique a atitude discriminatória.

Diante dessa realidade de homofobia na sociedade moderna como um todo, observou-se uma forte demanda social de sujeitos que coletivamente se percebem discriminados. Criou-se uma nova figura de linguagem e simbólica, o gay como representação social, como grupo, como coletivo. Sujeitos se identificam com a causa, da busca de fazer valer seus direitos. Ferrari (2004) caracteriza que a partir dos anos 1970, o movimento gay no Brasil teve crescente visibilidade, o que propiciou o surgimento de uma subcultura gay. Para o movimento, representava a construção de uma nova relação entre homossexualidade e sociedade. Para esse autor, o movimento gay organizado vem trabalhando com objetivos definidos, uma vez que:

[...] O objetivo do movimento é a construção dos sujeitos, responsável pelas mudanças de visões, posturas, hábitos, transformação das pessoas a partir de um conhecimento de si e do mundo. De forma consciente, o movimento gay surgiu a partir de uma preocupação com o entendimento do mundo, com a tentativa de esclarecer e dominar os parâmetros de sua organização e de classificação da homossexualidade, e com a demanda de desconstruir as 
identidades homossexuais cristalizadas em busca de novas possibilidades de vivências mais positivas. Portanto, se a ideia era pensar a organização do mundo e como esse grupo estava sendo explicado e se explicava a partir disso, isso significava pensar a política das identidades, não somente as identidades homossexuais, mas todas as identidades que dizem respeito e se relacionam com ela, seja as identidades de gênero ou aquelas vinculadas à orientação sexual (FERRARI, 2004, p. 2).

Na produção acadêmica dedicada à questão da homossexualidade e suas interseções com a cultura e sociedade, destaca-se a analítica queer. Diversos autores vêm se dedicando a fazer pesquisas que questionam a heterossexualidade como norma e a desconstruir o binarismo entre homem e mulher. A analítica queer propõe a combater a heteronormatividade, denunciando o seu pressuposto de heterossexualidade como natural e fundamental para a vida em sociedade (MISKOLCI, 2007). Segundo Souza e Carrieri (2010, p. 46):

[...] A analítica queer está fundamentada em Foucault, que defende uma visão pósidentitária e fragmentada em relação ao pensamento identitário/binário hegemônico sobre a sexualidade e os estudos de gênero. Tal visão é fundamental para o fomento de resistência e desenvolvimento de práticas organizacionais locais e empíricas que possam promover uma atuação e intervenção diante das práticas opressivas direcionadas não só à sexualidade, mas também a outras formas de opressão no local de trabalho.

Para Prado e Machado (2008), a heteronormatividade foi instituída e legitimada como preceito regulador das relações sociais por meio da difusão de ideias pejorativas de atribuição social acerca das práticas não heterossexuais, que associavam a essas noções a pecha de causadoras de doença e de perversão, naturalizando e obliterando a difusão de práticas homofóbicas em decorrência do imaginário constituído. Em decorrência do estabelecimento de tal distinção sexual, os sujeitos assumidamente homossexuais passaram a ser enquadrados em esferas inferiores da hierarquia social e a ser alvo de discriminações e inferiorizações, realidade de opressão invisibilizada como natural às relações de subordinação social.

Assim, desenvolveu-se:

[...] A forma particular de dominação simbólica de que são vítimas os homossexuais, marcados por um estigma que, à diferença da cor da pele ou da feminilidade, pode ser ocultado (ou exibido), impõe-se através de atos coletivos de categorização que dão margem a diferenças significativas, negativamente marcadas, e com isso a grupos ou categorias sociais estigmatizadas. Como em certos tipos de racismo, ela assume, no caso, a forma de uma negação da sua existência pública, visível. A opressão como forma de "invisibilização" traduz uma recusa à existência legítima, pública, isto é, conhecida e reconhecida, sobretudo pelo Direito, e por uma estigmatização que só aparece de forma realmente declarada quando o movimento reivindica a visibilidade. Alega-se, então, explicitamente, a "discrição" ou a dissimulação que ele é ordinariamente obrigado a se impor (BOURDIEU, 2003, p. 143-144, grifo nosso).

Nessa perspectiva, o ponto de vista do dominante, a doxa, torna-se baliza para as análises que o sujeito é capaz de estabelecer, uma vez que ele fora educado a partir de preceitos heterossexuais (BOURDIEU, 2003), tanto em relação a si mesmo e a sua relação com o mundo quanto em referência aos demais oprimidos.

A ruptura com a discriminação contra a homossexualidade, de hétero ou homossexuais, é, notadamente, uma meta do movimento "gay". Contudo, há fortes divergências quanto ao percurso a ser adotado:

[...] Percepções discordantes sobre os meios a serem empregados na conquista da visibilidade e do respeito desejados. Alguns defendem a afirmação de uma radical diferença por parte dos homossexuais e a demarcação de fronteiras nítidas separando-os dos heterossexuais. [...] Outros parecem militar no sentido de obter uma aceitação por parte da sociedade e dos heterossexuais. Nesse caso, o caminho seria marcado por compromissos, 
pela incorporação de algumas regras como a da discrição, da sobriedade e do recato. $\mathrm{O}$ resultado seria, segundo os defensores de tais posturas, o acesso menos conflituoso à igualdade de direitos e ao respeito por opções diferenciadas (LEONINI, 2004, p. 146).

Dessa forma, o campo de conflito está armado; contudo, o sujeito homossexual vive a disputa com capitais simbólicos que não são seus; opera com a doxa, com a opinião consensual que o exclui, que o distingue; estabelece formas de lutas, com base em nomos, leis, normas instituídas para manter os capitais simbólicos sob poder de quem os exclui. Como pode se operar a produção de novas verdades? Como o sujeito se situa diante do coletivo, que vive a contradição e o conflito entre o novo (a ser produzido) e a doxa dominante?

A psicanálise, enquanto clínica, tem discutido sobre como o sujeito se situa diante dos caminhos do coletivo, no caso do movimento gay. Para Miller (2006, p. 17-18), houve uma mudança cultural na visão do homossexual, se antes se situava no campo da estigmatização, hoje "vê-se cada vez menos motivos para não aceitar a homossexualidade como um estilo de vida, uma escolha de objeto, minoritária, é certo, mas tão defensável como qualquer outra". Esse autor afirma que todo homossexual em algum momento se situa em relação ao discurso do movimento gay, "acontece que o fato de não aderir à comunidade gay, de ser rebelde a ser capturado por seus ideais e práticas é, para um homossexual, ocasião para ter um sentimento de culpabilidade reforçado".

Santiago (2007, p.254) comenta que o

[...] termo gay surge para evidenciar que se o tédio, a tristeza estão do lado da rotina dos héteros; o carnaval, as coisas divertidas se encontram do outro lado. O movimento gay é um exemplo dessa oferta identificatória no mercado do gozo, visto que a simples disponibilidade de um significante novo é suficiente para uma identificação comunitária que busca contrapor-se à atopia do nomadismo.

Na sua percepção, o surgimento de novas formas de amor e gozo não acontece sem o surgimento de novos sintomas e novas angústias. "A inflexão da multiplicidade das soluções amorosas acarreta a adoção do imperativo de ter que se identificar com sua própria diferença, de tentar lidar, custe o que custar, com um significante mestre individualizado"(.SANTIAGO, 2007, p 254-5) Miller (2006, p. 21) afirma que o movimento gay opera buscando instituir um novo significante-mestre. Essa operação "coloca sobre o mercado dos valores e das figuras ideológicas uma representação social do homossexual como minoria, tendo seus direitos para reivindicar. [...] age por identificação metódica, quer dizer por sugestão". Nesta perspectiva, ser "gay" pode funcionar como esse novo significante-mestre, que, como um imperativo categórico, opera simbolicamente, criando um novo dispositivo de poder, em que todos que não se identificam com os padrões de sexualidade binária, têm que se identificar, agir como, estabelecendo uma nova naturalidade.

O discurso da comunidade gay promoveria a ideia de um coletivo, de comum, comunitário, em que a singularidade da demanda de cada sujeito escapole, fica fora dessa nova ordem discursiva. Socialmente, o sujeito vê-se compelido a se identificar com esse novo significante-mestre, exigindo, reivindicando seu lugar na cultura, um lugar no desejo do Outro, ou seja, um lugar de aceitação sociocultural. Miller (2006) faz, ainda, observações sobre a analítica queer, como outro viés, que procura ir além do regime do significantemestre, não buscando se sujeitar aos ditames da cultura, denunciando a cultura, a norma.

\section{Considerações Finais}

Na contemporaneidade, o indivíduo, como mostrado por Birman (2007), tem sua subjetividade marcada pelo narcisismo, pela impossibilidade de perceber o outro na sua diferença. O sujeito da sociedade do espetáculo vê no outro somente um objeto para seu uso. O registro especular é apenas o do engrandecimento da própria 
imagem. Assim, o sujeito autocentrado "percebe" o outro nos limites do seu interesse. Socialmente, a solidariedade entre os indivíduos perde valor, dado que a solidariedade se fundamenta na alteridade, isto é, no reconhecimento do outro como singular e diferente. Nessa perspectiva o credo atual é saquear o outro no que ele tem essencial.

Por um lado, os sujeitos homossexuais inseridos na sociedade do espetáculo são compelidos a se expressar, consumir, manifestar seus desejos, percebendo-se livres, e acreditando nas possibilidades de suas escolhas. Do outro lado, há o mundo do trabalho, em que esse sujeito desejante acredita ser possível expressar sua singularidade e depara-se com as exigências modernas do capital do trabalho individualizado, do cada um por si, da exigência de desempenho, da negação do relacional.

Esse conflito estará expresso, segundo Dejours (2008), na forma de sofrimento no trabalho. O sujeito-alvo da uma violência simbólica de uma sociedade sob a dominação masculina e heterossexista se vê limitado na sua subjetividade, nas possibilidades de manter sua integridade psíquica, sua imagem e dignidade social. Tal sujeito tolhido poderá, então, também estar limitado no cotidiano de seu trabalho, ou seja, suas possibilidades de reconhecimento, de mobilização afetiva e intelectual para com o trabalho, de realização enquanto trabalhador estarão restritas. A violência simbólica pode imputar a não construção de laços de identificação com o trabalho (LANCMAN, 2008).

No âmbito das organizações, as políticas de gestão de recursos humanos são de incentivo à competição e à ênfase na produtividade, tornando ainda mais fragilizadas e estressantes as relações de trabalho. Esse contexto evidencia uma crescente violência no espaço do trabalho, desencadeadora de sofrimento e adoecimento psíquico. Concomitantemente, a gestão das políticas de diversidade, por vezes, reforça o preconceito, mascarando as diferenças e buscando administrar os resultados (ECCEL e FLORES-PEREIRA, 2008). Sob o prisma das análises de Bordieu, as políticas de diversidade direcionadas a homossexuais podem ser observadas como reafirmando padrões de "normalidade" (heterossexual) e desvalorizando a diferença.

É nesse cenário de violência no espaço organizacional que o trabalhador homossexual busca a sua expressão como sujeito trabalhador. Sob o espectro dos discursos do movimento gay e da heteronormatividade e com as possibilidades de novas construções subjetivas que encerram. Sob esse espectro esse sujeito buscará reconhecimento, dignidade e identidade profissional. Fica, contudo, a questão: como pensar no campo organizacional relações de trabalho, no qual a singularidade de cada um possa se expressar, no qual os diversos sujeitos trabalhadores encontrem um espaço de identificação e criação de laços com o trabalho, no qual as relações não sejam marcadas pela violência, mas pelo reconhecimento da alteridade dos sujeitos?

\section{Referências}

ARMADA, C. A. S. Assédio moral no trabalho. 2006. Disponível m: $<$ http://www.odireito.com/default.asp?SecaoID $=10 \&$ SubSecao $=1 \&$ ConteudoID $=000188 \&$ SubSecaoID $=28>$. Acesso em: 01 Jun. 2006.

BARRETO, M. M. S. Violência, saúde e trabalho: uma jornada de humilhações. São Paulo: Educ, 2003.

Assédio moral: a violência sutil - análise epidemiológica e psicossocial do trabalho no Brasil. 2005, Tese (Doutorado em Psicologia Social) - Pontifícia Universidade Católica de São Paulo, São Paulo, 2005. 190p.

BIRMAN, J. Mal-estar na atualidade: a psicanálise e as novas formas de subjetivação. 6. ed. Rio de Janeiro: Civilização Brasileira, 2007.

BOURDIEU, P. Questões de sociologia. Rio de Janeiro: Marco Zero, 1983.

Razões práticas: sobre a teoria da ação. 4. ed. Campinas, SP: Papirus, 1996. 
. A dominação masculina. 3. ed. Rio de Janeiro: Bertrand Brasil, 2003.

O poder simbólico. 10. ed. Rio de Janeiro: Bertrand Brasil, 2007.

CROTEAU, J. M.; HEDSTROM, S. M. Integrating commonality and difference: the key to career counseling with lesbian women and gay man. The Career Development Quartely, v. 42, n. 3, p. 201-209, 1993.

DÉBORD, G. A sociedade do espetáculo: comentários sobre a sociedade do espetáculo. Rio de Janeiro: Contraponto, 1997.

DEJOURS, C. A loucura do trabalho: estudo de psicopatologia do trabalho. São Paulo: Cortez, 1992.

A banalização da injustiça social. Rio de Janeiro: Ed. FGV, 1999.

Adendum: da psicopatologia à psicodinâmica do trabalho. In: LACMAN, S.; SZNELWAR, L. (Org.). Cristophe Dejours: da psicopatologia à psicodinâmica do trabalho. 2. ed. Rio de Janeiro: Paralelo 15/Fiocruz, 2008. p. 49-106.

ECCEL, C. S.; FLORES-PEREIRA, M. T. A inserção da "diversidade" homossexual em uma livraria de shopping center: um estudo crítico. Rio de Janeiro. Anais... Rio de Janeiro: Anpad, 2008.

ELliOT, J. E. Career development with lesbian and gay clients. The Career Development Quartely, v. 42, n. 3, p. 210-226, 1993.

FERRARI, A. Revisando o passado e construindo o presente: o movimento gay como espaço educativo. Revista Brasileira de Educação, n. 25, p. 105-115, jan./abr. 2004.

FREITAS, M. E. Assédio moral e assédio sexual: faces do poder perverso nas organizações. RAE, v. 41, n. 2, p. 8-19, abr./jun. 2001.

FREITAS, M. E.; HELOANI, J. R.; BARRETO, M. Assédio moral no trabalho. São Paulo: Cengage Learning, 2008.

GALEÃO-SILVA, L. G.; ALVES, M. A. A crítica do conceito de diversidade em organizações. In: ENCONTRO DE ESTUDOS ORGANIZACIONAIS, 2002, Recife. Anais... Rio de Janeiro: Anpad, 2002.

GARBIN, A. C. Representações na mídia impressa sobre assédio moral no trabalho. 2009. Dissertação (Mestrado em Saúde Pública). Programa de Pós-Graduação em Saúde Pública, Universidade de São Paulo, São Paulo, 2009. 169 p.

HEREK, G. M. Stigma, prejudice, and violence against lesbians and gay men. In: GONSIOREK, J. C.; WEINRICH, J. D. Homosexuality: research implications for public policy. Newbury Park: Sage, 1991. p. 60-80.

HIRIGOYEN, M.-F. Mal-estar no trabalho: redefinindo o assédio moral. Rio de Janeiro: Bertrand Brasil, 2002.

Assédio moral: a violência perversa no cotidiano. 7. ed. Rio de Janeiro: Bertrand Brasil, 2005.

JARDIM, G. A. S. O individualismo na cultura moderna. Caos. Revista Eletrônica de Ciências Sociais, n. 7, p. 23-31, set. 2004.

JOTA, F. S. S. V. B. O. O meu prazer e meu maior desejo: uma análise da sexualidade feminina na contemporaneidade. Revista Intercâmbio de Congressos de Humanidades, p. 1-14, out. 2007. Disponível m: http://unb.revistaintercambio.net.br/24h/pessoa/temp/anexo/1/115/119.pdf. Acesso em: 13/02/2013

LANCMAN, S. O mundo do trabalho e a psicodinâmica do trabalho. In: LANCMAN, S.; SZNELWAR, L. (Org.). Christophe Dejours: da psicopatologia à psicodinâmica do trabalho. 2. ed. Rio de Janeiro: Paralelo 15/Fiocruz, 2008. p. 23-34.

LANTÉRI-LAURA, G. A leitura das perversões. Rio de Janeiro: Zahar, 1994. 
LEONINI, L. Os clientes das prostitutas: algumas reflexões a respeito de uma pesquisa sobre prostituição em Milão. In: SCHPUN, M. R. Masculinidades. São Paulo: Boitempo editorial; Santa Cruz do Sul: Edunisc, 2004.

LIMA, M. E. A. A psicopatologia do trabalho. Psicologia: Ciência e Profissão, v. 18, n. 2, p. 10-15, 1998.

LIPOVETSKY, G. A era do vazio. Lisboa/São Paulo: Relógio d’Água, 1983.

MERLO, A. R. C. Transformações no mundo do trabalho e a saúde. In: O valor simbólico do trabalho e o sujeito contemporâneo. Porto Alegre: Artes e Ofícios, 2000. 304 p

MILLER, J. Gays em análise? Opção Lacaniana, n. 47, p. 15-22, dez. 2006.

MISKOLCI, R. A teoria queer e a questão das diferenças. In: CONGRESSO DE LEITURA DO BRASIL, 2007, Campinas. Anais... Campinas, SP: Associação de Leitura do Brasil, 2007. v. 1, p. 1-19.

MOLINIER, P. Psychodynamique du travail et identité sexuelle. 1995. Tese (Doutorado em Psicologia). Conservatoire National des Arts et Métiers, Paris, 1995, 273p.

Psicodinâmica do trabalho e relações sociais de sexo: um itinerário interdisciplinar. 1988-2002. Revista Produção, v. 14, n. 3, p 14-26, 2004. Acesso em: 4 dez. 2012.

NARDI, H. C. Nas tramas do humano: quando a sexualidade interdita o trabalho. In: POCAHY, F. Rompendo o silêncio: homofobia e heterossexismo na sociedade contemporânea. Políticas, teoria e atuação. Porto Alegre: Nuances, 2007.

NASCIMENTO, S. A. C. M. O assédio moral no ambiente de trabalho. Revista LTr, 68-08/922-930, ago. 2004. Disponível em: <http://www1.jus.com.br/doutrina/texto.asp?id=5433>. Acesso em: 29 out. 2004.

OFICINA INTERNACIONAL DEL TRABAJO OIT. Conferência Internacional del Trabajo, 96. Aplicación de las normas Internacionales del trabajo. Genebra: Oficina Internacional del Trabajo, 2007.

PIMENTA, S. M.; CORREA, M. L. (Org.). Gestão, trabalho e cidadania. Belo Horizonte: Autêntica, 2001.

PRADO, M. A.; MACHADO, F. V. Preconceito contra homossexuais: a hierarquia da invisibilidade. São Paulo: Cortez, 2008.

SANTIAGO, J. Atualidade clínica da homossexualidade masculina: solução ou escolha de objeto. Psicologia em Revista, v. 13, n. 2, p 253-266, dez. 2007.

SATO, L. Saúde e controle no trabalho: feições de um antigo problema. In: JACQUES, M. G.; CODO, W. (Org.). Saúde mental e trabalho: leituras. Petrópolis, RJ: Vozes, 2002. p. 31-49.

SOUZA, E. M.; CARRIERI, A. P. A analítica queer e seu rompimento com a concepção binária de gênero. Revista de Administração Mackenzie, v. 11, n. 3, p. 46-70, 2010.

THIRY-CHERQUES, H. R. Pierre Bourdieu: a teoria na prática. Revista de Administração Pública, v. 40, n. 1, p. $27-$ 55, jan./fev. 2006.

ZALUAR, A.; LEAL, M. C. Violência extra e intramuros. RBCS, v. 16, n. 45, p.145-164, fev. 2001. 